\title{
Asymptomatic Central Pontine Myelinolysis: A Case Report
}

\author{
Syed Omar Shah ${ }^{\mathrm{a}}$ Arthur Wang ${ }^{\mathrm{b}}$ Lakshmi Mudambi ${ }^{\mathrm{c}}$ \\ Nasreen Ghuznavi ${ }^{\mathrm{C}}$ Robert Fekete ${ }^{\mathrm{a}}$ \\ Departments of ${ }^{a}$ Neurology, ${ }^{b}$ Neurosurgery, and ${ }^{c}$ Medicine, New York Medical \\ College, Valhalla, N.Y., USA
}

Key Words

Central pontine myelinolysis $\cdot$ Hyponatremia $\cdot$ Alcoholism $\cdot$ Malnutrition

\begin{abstract}
Introduction: Central pontine myelinolysis (CPM) is an acquired demyelinating lesion of the basis pontis that typically occurs after rapid correction of hyponatremia. There are only a few reported cases of patients without symptoms that have demonstrated CPM on imaging. Case Presentation: We report the case of a 26-year-old Hispanic male with history of alcohol abuse who was transferred to our medical center for acute onset diffuse abdominal pain. During his work up, a computed tomography scan demonstrated a large pancreatic mass. He underwent an endoscopic guided biopsy which demonstrated a rare and aggressive natural killer T cell lymphoma. His laboratory values were consistent with hyponatremia, which the medical team gently corrected. An MRI was performed for staging purposes which revealed findings consistent with CPM. A full neurological exam demonstrated no deficits.
\end{abstract}

Materials and Methods: We conducted a PubMed search using the following keywords: asymptomatic, central, pontine, and myelinolysis in order to find other case reports of asymptomatic CPM.

Results: Of the 29 results, only 6 previous case reports with English language abstracts of asymptomatic CPM were present since 1995.

Conclusion: Despite slow correction of hyponatremia, CPM can be an important consequence, especially in patients with chronic alcoholism. Although this patient did not demonstrate any neurological deficits, the fact that there were changes seen on MRI should caution physicians in aggressively treating hyponatremia. Furthermore, if there is a decision to treat, then fluid restriction and reversal of precipitating factors (i.e. diuretics) should be used initially, unless there is concern for hypovolemia. 


\section{Introduction}

Central pontine myelinolysis (CPM) is an acquired demyelinating lesion of the basis pontis that typically occurs after rapid correction of hyponatremia. It is an uncommon condition with predilection for the central portion of the basis pontis, although axons in the putamina, caudate nuclei, thalami, cerebellum, splenium of the corpus callosum, and subcortical white matter are other extrapontine sites that are sometimes involved either separately or in concert with the pontine lesion [1, 2]. CPM is most often found in patients with chronic alcoholism, malnutrition, hyponatremia, liver disease, liver transplants, systemic hypotension and infections [3]. Patients typically develop symptoms ranging from quadriplegia and pseudobulbar palsy to dysphagia or anarthria. The case below demonstrates lesions consistent with CPM but without clinical exam findings.

\section{Case Report}

A 26-year-old Hispanic male with history of alcohol abuse presented with acute onset diffuse abdominal pain. There was a 1-month history of intermittent abdominal pain, lethargy, and early satiety with resulting $9 \mathrm{~kg}$ weight loss. He was intubated for airway protection after an episode of hematemesis. He remained awake, and hemodynamically stable. No gross abnormalities were detected on physical examination. Laboratory studies revealed hemoglobin and hematocrit of 11.1 $\mathrm{g} / \mathrm{dl}$ and $32.4 \%$, respectively, with a platelet count of 86,000 per microliter. The only other abnormalities were serum sodium of $130 \mathrm{IU} / \mathrm{l}$, aspartate aminotransferase and alanine transaminase at 152 and $166 \mathrm{IU} / \mathrm{l}$, alkaline phosphatase at $186 \mathrm{IU} / \mathrm{l}$ and amylase and lipase at 86 and $105 \mathrm{U} / \mathrm{l}$, respectively.

On the night of admission, a computed tomography (CT) scan of the abdomen showed a large pancreatic mass of $12 \times 11 \times 6.5 \mathrm{~cm}$ in size encasing the second and third portions of the duodenum, extending retroperitoneally and abutting the adjacent inferior vena cava and abdominal aorta. During his hospital stay, the patient underwent an endoscopic guided biopsy of the mass by the gastroenterology team and fine needle aspiration bone marrow biopsy. The findings revealed a rare and aggressive natural killer T cell lymphoma. He was promptly started on chemotherapy.

In light of his hyponatremia on presentation, the medical ICU team decided to gently correct his sodium using salt tablets and normal saline. His daily sodium levels are graphed in fig. 1 . Each value can be seen in online supplementary table 1 (www.karger.com/doi/10.1159/000345225). An MRI of the brain was performed on hospital day 8 for staging purposes and is displayed in fig. 2 . Although no lesions were demonstrated to be consistent with lymphoma, there were fluid attenuation inversion recovery (FLAIR) and T2-weighted changes consistent with CPM. The patient did not have a previous MRI of the brain for comparison. Following the new MRI findings, the neurology team was consulted for a detailed exam. Neurological exam did not demonstrate any focal deficits.

\section{Discussion}

The manifestations of CPM range from asymptomatic to death. Typical symptoms include behavioral disturbances, confusion, mutism, dysarthria, dysphagia, bulbar and pseudobulbar paresis, hyperreflexia, quadriplegia, and seizures $[2,4]$. Locked-in state can occur and coma is uncommon $[2,4]$. Acute hyponatremia $(\leq 48 \mathrm{~h})$ generally causes more severe symptoms as compared to chronic hyponatremia $(\geq 48 \mathrm{~h})$ but individuals with chronic hyponatremia are at higher risk for developing CPM [2]. 
Pathologically CPM is described as a symmetric, sharply demarcated lesion in the basis pontis. There is a loss of oligodendrocytes, destruction of myelin sheaths and preservation of neuronal cell bodies and axons. Inflammation is absent and evidence of disruption of the blood-brain barrier may be present [2]. The lesion of CPM has a characteristic radiographic appearance. Although CT may be normal for several days to 2 weeks, the typical CT findings include symmetric hypo-dense areas in the basis pontis and extra-pontine regions with no associated mass effect [2]. An MRI is more sensitive and on T2-weighted and FLAIR images, CPM appears as a symmetric hyper-intense signal in the central pons. On T1-weighted MRI, the lesion is hypo-intense and noncontrast enhancing. MRI diffusion-weighted imaging is most sensitive and can detect lesions within $24 \mathrm{~h}$ of development of symptoms and shows a hyper-intense region [4]. The severity of the lesion does not correlate with the severity of symptoms but the lesion will decrease in size and intensity on T2-weighted and FLAIR images as clinical symptoms subside [2].

The exact pathogenesis of CPM is still under debate. Previous clinical and laboratory studies suggest that myelinolysis is due to cellular stress which is the result of fluctuating osmotic forces and ion shifts that lead to changes in cell volume and cell membrane function. Other clinical studies have shown that myelinolysis may be due to the brain's overshoot of sodium during correction of hyponatremia or compression of myelin by edematous cellular elements $[3,5]$.

In 1959, Adams et al. [6] first described CPM in 4 patients. Three were malnourished alcoholics and 1 was malnourished but not an alcoholic. Only 2 had symptoms of CPM. We performed a PubMed search with the following keywords: asymptomatic, central, pontine, and myelinolysis in order to find other reports of asymptomatic CPM. Of the 29 results, we found only 6 previous case reports with English language abstracts of patients with alcoholism, malnutrition, or liver transplants that were diagnosed with asymptomatic CPM since 1995 [3, 7-11].

In addition, a postmortem study of 3,247 brains found 15 cases of CPM incidentally. All were asymptomatic. Six had active lesions and 9 had remote lesions as defined pathologically. In the active group, 5 individuals received rapid and sustained treatment of hyponatremia during the appropriate time frame [12].

In patients who develop acute hyponatremia, the urinary sodium concentration is often greater than $40 \mathrm{mmol} / \mathrm{l}$, and the plasma urea concentration is low, whereas in chronic hyponatremia, the urinary sodium concentration is usually less than 20 $\mathrm{mmol} / \mathrm{l}$, and the plasma urea concentration is often high [13]. The decision to treat hyponatremia or not is still up for debate as some suggest only fluid restriction and reversal of any precipitating factor to manage these patients rather than more aggressive measures such as $0.9 \%$ saline [14]. While the rate of correction of chronic hyponatremia is generally recommended to be slow to reduce the incidence of CPM, at least nine correction rates have been reported: from 2-3 mmol/l/day up to 25 $\mathrm{mmol} / \mathrm{l} /$ day $[15,16]$. The general consensus, however, is to correct no greater than 12 $\mathrm{mmol} / \mathrm{l} /$ day. The patient in this case was corrected at a much slower rate than 12 $\mathrm{mmol} / \mathrm{l} /$ day, demonstrating the difficulty in controlling sodium correction to prevent CPM. Moreover, it has been recognized that certain patients such as those who suffer from chronic alcoholism, as our patient did, or the malnourished are at higher risk for developing CPM despite of a slow correction [17]. 
This case clearly demonstrates that despite slow correction of hyponatremia, CPM can be an important consequence, especially for patients suffering from malnutrition or alcoholism. Although this patient did not demonstrate any neurological deficits, the fact that there were changes seen on MRI should caution physicians in aggressively treating hyponatremia. Furthermore, if there is a decision to treat, then fluid restriction and reversal of precipitating factors (i.e. diuretics) should be used initially, unless there is concern for hypovolemia [15]. Lastly, there are only a few reported cases of asymptomatic CPM and we hope to raise awareness of this entity.

\section{Disclosure Statement}

Dr. Fekete received honoraria from Medlink, Inc., and serves as consultant for Teva Neuroscience, Inc., and Lundbeck, LLC.

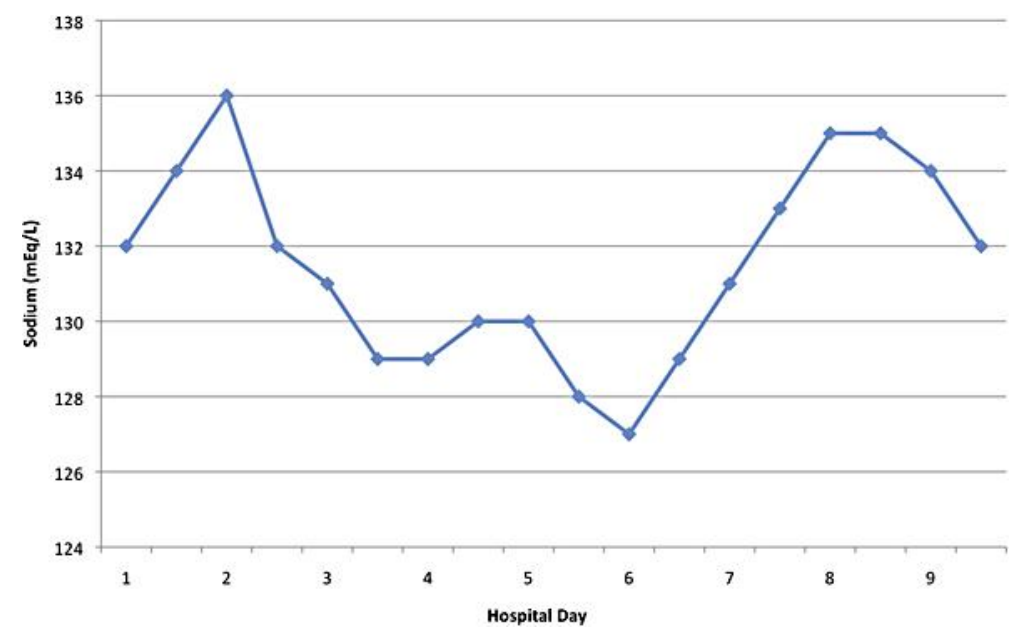

Fig. 1. Sodium values measured every $12 \mathrm{~h}$ over the 9-day hospital course of the patient. See online supplementary table 1 for each sodium value. 

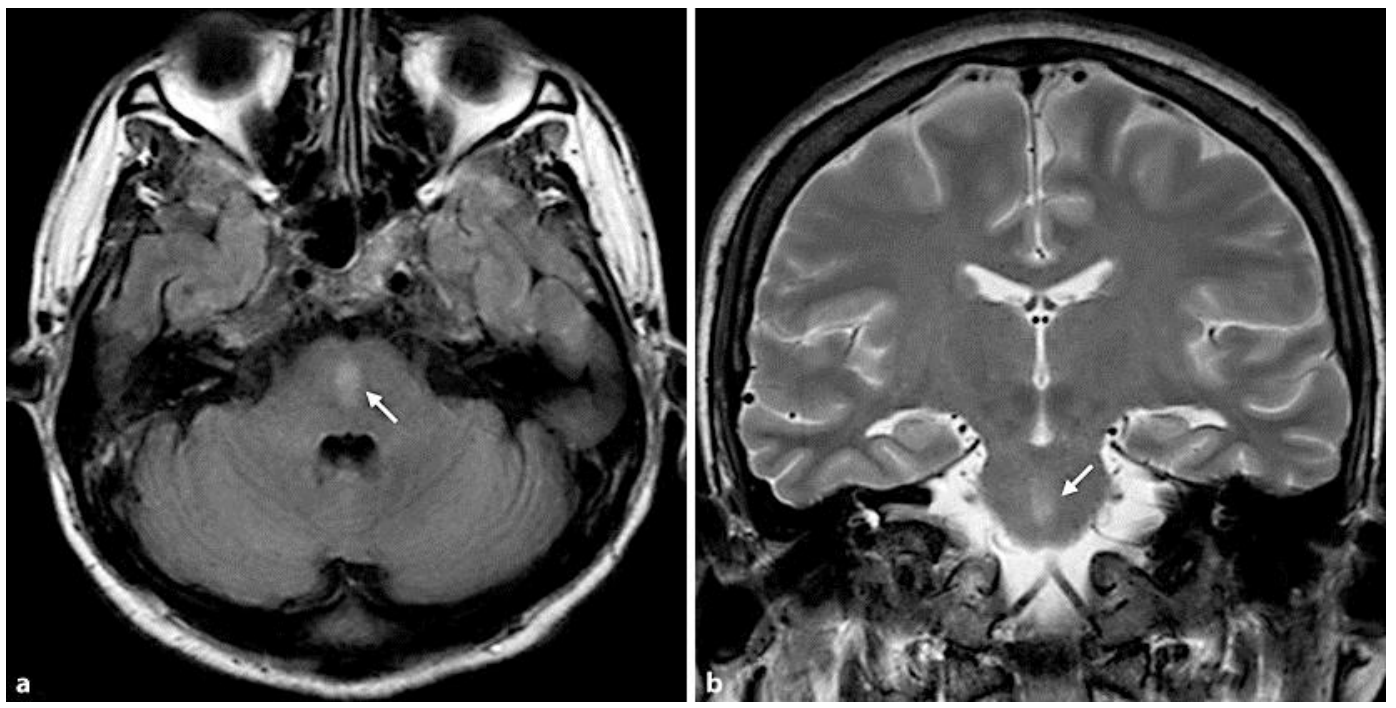

Fig. 2. a Axial FLAIR and b coronal T2-weighted images demonstrate increased signal in the central pons. Images were acquired on a Philips Achieva 3.0 Tesla MRI. Technical parameters on axial FLAIR include: TE $125 \mathrm{~ms}$ and TR 11,000 ms with a flip angle of 90 and coronal T2-TSE include: TE $80 \mathrm{~ms}$ and TR 3,000 ms with a flip angle of 90 .

\section{References}

1 Bourgouin PM, Chalk C, Richardson J, et al: Subcortical white matter lesions in osmotic demyelination syndrome. AJNR Am J Neuroradiol 1995;16:1495-1497.

-2 Hurley RA, Filley CM, Taber KH: Central pontine myelinolysis: a metabolic disorder of myelin. J Neuropsychiatry Clin Neurosci 2011;23:369-374.

-3 Lupato A, Fazio P, Fainardi E, Edoardo C, Casetta I, Granieri E: A case of asymptomatic pontine myelinolysis. Neurol Sci 2010;31:361-364.

4 Bernardini GL, Mancall EL: Central pontine myelinolysis; in Rowland LP, Pedley TA (eds): Merritt's Neurology, ed 12th. Lippincott Williams and Wilkins, 2010, pp 924-926.

5 Cramer SC, Stegbauer KC, Schneider A, Mukai J, Maravilla KR: Decreased diffusion in central pontine myelinolysis. Am J Neuroradiol 2001;22:1476-1479.

6 Adams RD, Victor M, Mancal LE: Central pontine myelinolysis. Arch Neurol Psychiatry 1959;91:154-172.

7 Strub MU, Steck AJ, Fuhr P: Asymptomatic central pontine myelinolysis. Neurology 1999;53:914.

8 Fornalska Z, Chmielowski M, Klimek A: [A case of asymptomatic central pontine myelinolysis]. Neurol Neurochir Pol 1998;32:663-670.

9 Girmenia F, Colosimo C, Di Biasi C, Faroni J, Pozzilli C: Central pontine myelinolysis: report of an asymptomatic case. Ann Ital Med Int 1995;10:53-54.

$\checkmark 10$ Maure Noia B, Sopeña B, Argibay Filgueira A, Arias M: [Asymptomatic central pontine myelionolysis and HIV infection]. Neurologia 2009;24:136-137.

11 Razvi SS, Leach JP: Asymptomatic pontine myelinolysis. Eur J Neurol 2006;13:1261-1263.

12 Fryer JP, Fortier MV, Metrakos P, Verran DJ, Asfar SK, Pelz DM, Wall WJ, Grant DR, Ghent CN: Central pontine myelinolysis and cyclosporine neurotoxicity following liver transplantation. Transplantation 1996;61:658-661.

13 Humes HD: Disorders of water metabolism; in Kokko JP, Tannen RL (eds): Fluids and Electrolytes. Philadelphia, WB Saunders, 1986, pp 118-149.

14 Harris CP, Townsend JJ, Baringer JR: Symptomatic hyponatraemia: can myelinolysis be prevented by treatment? J Neurol Neurosurg Psychiatry 1993;56:626-632. 
15 Martin RJ: Central pontine and extrapontine myelinolysis: the osmotic demyelination syndromes. J Neurol Neurosurg Psychiatry 2004;75(suppl 3):iii22-iii28.

16 Ayus JC, Krothapalli RK, Arieff AI: Changing concepts in treatment of severe symptomatic hyponatremia. Rapid correction and possible relation to central pontine myelinolysis. Am J Med 1985;78:897-902.

17 Omari A, Kormas N, Field M: Delayed onset of central pontine myelinolysis despite appropriate correction of hyponatraemia. Intern Med J 2002;32:273-274. 